\title{
NSAID intolerance: it is not always what it seems
}

\author{
Tatjana Pecaric Petkovic ${ }^{1 *}$, Werner J Pichler ${ }^{2}$, Oliver Hausmann ${ }^{3}$ \\ From 6th Drug Hypersensitivity Meeting (DHM 6) \\ Bern, Switzerland. 9-12 April 2014
}

Case A: 42 year old female patient without asthma or polyposis nasi presented with palmar and plantar pruritus, urticaria, facial angioedema and dyspnea on two occasions: 2 and 4 hours after the intake of two structurally independent NSAIDs (diclofenac $75 \mathrm{mg}$, mefenamic acid $500 \mathrm{mg}$ ). In both instances, pantoprazole, a proton pump inhibitor (PPI), was prescribed for gastric protection. A non-allergic NSAID intolerance was suspected and avoidance of all classical cyclooxygenase (COX)-1 inhibitors recommended. Regardless, the patient's husband insisted on further allergological work-up remembering one unproblematic intake of mefenamic acid $(500 \mathrm{mg}$ ) between the two events. Surprisingly, scratch testing was positive for pantoprazole only. This rare sensitization could be confirmed in basophil activation test (BAT). On further questioning the patient remembered that she forgot to take her pantoprazole comedication when she transiently tolerated the mefenamic acid. The patient refused a provocation test with an alternative PPI. Due to their close structural relationship avoidance of all PPI was recommended. No general restriction for NSAIDs was necessary, and mefenamic acid was tolerated again. For long-term non-irritating anti-inflammatory pain treatment a COX-2 inhibitor (etoricoxib $30 \mathrm{mg}$ ) was advocated and well-tolerated.

\section{Conclusion}

Intolerance to NSAIDs is frequent, but not all presumably "clear" cases are a classical NSAID intolerance, especially if the co-medication is known to cause anaphylaxis as well. This case supports the increasing numbers of reports showing PPI intake intolerance. A typical "pseudoallergic" clinical presentation alone does not exclude a true IgE-mediated allergy to a seemingly harmless co-medication. Thus, in patients with the frequent combination of NSAID and PPI a scratch test

Department of Rheumathology, Allergology and Clinical Immunology, Switzerland

Full list of author information is available at the end of the article with the incriminated PPI is advisable. BAT can help to substantiate less reliable and reproducible skin test methods, like scratch test and is also useful to identify an alternative PPI.

\section{Authors' details}

${ }^{1}$ Department of Rheumathology, Allergology and Clinical Immunology, Switzerland. ${ }^{2}$ Inselspital, University Hospital of Bern, Department of Rheumatology, Allergology and Immunology, Berne, Switzerland.

${ }^{3}$ Löwenpraxis, Zurich, Switzerland.

Published: 18 July 2014

doi:10.1186/2045-7022-4-S3-P7

Cite this article as: Petkovic et al:: NSAID intolerance: it is not always what it seems. Clinical and Translational Allergy 2014 4(Suppl 3):P7.

\section{Submit your next manuscript to BioMed Central and take full advantage of: \\ - Convenient online submission \\ - Thorough peer review \\ - No space constraints or color figure charges \\ - Immediate publication on acceptance \\ - Inclusion in PubMed, CAS, Scopus and Google Scholar \\ - Research which is freely available for redistribution \\ Submit your manuscript at www.biomedcentral.com/submit}

